\title{
The LIFE Cognition Study: design and baseline characteristics
}

This article was published in the following Dove Press journal:

Clinical Interventions in Aging

27 August 2014

Number of times this article has been viewed

\section{Kaycee M Sink' \\ Mark A Espeland ${ }^{2}$ \\ Julia Rushing ${ }^{2}$ \\ Cynthia M Castro ${ }^{3}$ \\ Timothy S Church ${ }^{4}$ \\ Ronald Cohen ${ }^{5}$ \\ Thomas M Gill ${ }^{6}$ \\ Leora Henkin ${ }^{2}$ \\ Janine $M$ Jennings ${ }^{7}$ \\ Diana R Kerwin ${ }^{8}$ \\ Todd M Manini ${ }^{5}$ \\ Valerie Myers ${ }^{9}$ \\ Marco Pahor ${ }^{5}$ \\ Kieran F Reid ${ }^{10}$ \\ Nancy Woolard' \\ Stephen R Rapp" \\ Jeff D Williamson'}

\section{On behalf of LIFE Investigators}

'Department of Internal Medicine, Section on Gerontology and Geriatric Medicine, Sticht

Center on Aging, Wake Forest School of Medicine,

Winston-Salem, NC, USA; '2Department

of Biostatistical Sciences, Wake Forest School

of Medicine, Winston-Salem, NC, USA; ${ }^{3}$ Stanford

Prevention Research Center, Stanford University

School of Medicine, Stanford, CA, USA;

${ }^{4}$ Pennington Biomedical, Louisiana State University,

Baton Rouge, LA, USA; ${ }^{5}$ nstitute on Aging and

Department of Aging and Geriatric Research,

University of Florida, Gainesville, FL, USA; ${ }^{6}$ Yale

School of Medicine, Department of Internal

Medicine, New Haven, CT, USA; ${ }^{7}$ Department

of Psychology, Wake Forest University, Winston-

Salem, NC, USA; ${ }^{8}$ Texas Alzheimer's and Memory

Disorders, Texas Health Presbyterian Hospital

Dallas, TX, USA; ${ }^{9} \mathrm{~K}$ lein Buendel, Inc., Golden,

CO, USA; ${ }^{10}$ Nutrition, Exercise Physiology and

Sarcopenia Laboratory, Jean Mayer United States

Department of Agriculture Human Nutrition

Research Center on Aging, Tufts University,

Boston, MA, USA; "'Department of Psychiatry

and Behavioral Medicine, Wake Forest School

of Medicine, Winston-Salem, NC, USA

Correspondence: Kaycee M Sink Sticht Center on Aging, Wake Forest School of Medicine, One Medical Center Blvd, Winston Salem, NC 27I57, USA

Tel + I 336 7I3 8560

Email kmsink@wakehealth.edu
Abstract: Observational studies have shown beneficial relationships between exercise and cognitive function. Some clinical trials have also demonstrated improvements in cognitive function in response to moderate-high intensity aerobic exercise; however, these have been limited by relatively small sample sizes and short durations. The Lifestyle Interventions and Independence for Elders (LIFE) Study is the largest and longest randomized controlled clinical trial of physical activity with cognitive outcomes, in older sedentary adults at increased risk for incident mobility disability. One LIFE Study objective is to evaluate the effects of a structured physical activity program on changes in cognitive function and incident all-cause mild cognitive impairment or dementia. Here, we present the design and baseline cognitive data. At baseline, participants completed the modified Mini Mental Status Examination, Hopkins Verbal Learning Test, Digit Symbol Coding, Modified Rey-Osterrieth Complex Figure, and a computerized battery, selected to be sensitive to changes in speed of processing and executive functioning. During follow up, participants completed the same battery, along with the Category Fluency for Animals, Boston Naming, and Trail Making tests. The description of the mild cognitive impairment/dementia adjudication process is presented here. Participants with worse baseline Short Physical Performance Battery scores (prespecified at $\leq 7$ ) had significantly lower median cognitive test scores compared with those having scores of 8 or 9 with modified Mini Mental Status Examination score of 91 versus (vs) 93, Hopkins Verbal Learning Test delayed recall score of 7.4 vs 7.9, and Digit Symbol Coding score of 45 vs 48 , respectively (all $P<0.001$ ). The LIFE Study will contribute important information on the effects of a structured physical activity program on cognitive outcomes in sedentary older adults at particular risk for mobility impairment. In addition to its importance in the area of prevention of cognitive decline, the LIFE Study will also likely serve as a model for exercise and other behavioral intervention trials in older adults.

Keywords: exercise, physical activity, older adults, dementia

\section{Introduction}

Evidence is rapidly accumulating to support the benefits of exercise for the brain and cognitive function. In human and animal studies, exercise has been shown to have beneficial effects on growth factors such as brain-derived neurotrophic factor, neurogenesis, resistance to brain insult, perfusion, connectivity, the promotion of gene expression fostering brain plasticity, ${ }^{1-5}$ and brain volume.$^{6-9}$ Exercise has also been shown to decrease beta-amyloid plaques in transgenic Alzheimer's mice. ${ }^{10}$ In addition to biologic data, there are considerable epidemiologic data to support a beneficial relationship between exercise and cognition. ${ }^{1-13}$ For example, Yaffe et al found that among 5,925 community-dwelling older women, those who reported higher baseline physical activity (PA) (blocks walked per week) had significantly less cognitive decline over the next 8 years. ${ }^{11}$ Several small randomized controlled trials (RCTs) have demonstrated improvements in executive function and memory in response to 
aerobic exercise. ${ }^{14,15}$ An RCT of a home exercise program in participants with mild cognitive impairment (MCI) found a small benefit of exercise on global cognition measured by the Alzheimer's Disease Assessment Scale - Cognitive subscale. ${ }^{16}$ However, the control group also had very high levels of exercise ( $>10,000$ steps walked per day), which may have reduced the overall effect size. No RCT has been conducted with sufficient size and duration to assess the longterm impact of a PA intervention on cognitive function.

The Lifestyle Interventions and Independence for Elders (LIFE) Cognition Study builds on its pilot study data that demonstrated significant improvement in physical function and potential benefit for cognitive function. ${ }^{17}$ This large-scale, Phase III RCT aims to overcome the limitations of previous exercise trials by enrolling a larger sample of physically at-risk older adults and following their cognitive function for at least 2 years, including assessment for incident MCI and dementia. Here we describe the LIFE Cognition Study design, methods, and baseline characteristics of the cohort. The primary goal of the LIFE Cognition Study is to determine whether structured PA results in relatively better cognitive function and/ or reduces the risk for incident MCI or dementia (MCI/D) compared with successful aging health education (SA).

\section{Methods}

\section{Participants and intervention}

The LIFE Study is a Phase III multicenter RCT (ClinicalTrials.gov identifier NCT01072500) designed to compare a moderate-intensity PA program with SA to assess effects on major mobility disability, defined as inability to walk $400 \mathrm{~m}$. The details of the LIFE Study design and intervention have already been published. ${ }^{18}$ Briefly, participants $(n=1,635)$ were enrolled across eight field centers (University of Florida, Gainesville; Northwestern University; Pennington Biomedical Research Center; Stanford University; Tufts University; University of Pittsburgh; Wake Forest University; and Yale University). At baseline, the participants were 70-89 years old, sedentary, and at high risk for mobility disability, based on a Short Physical Performance Battery (SPPB) ${ }^{19,20}$ score $\leq 9$, but were able to walk $400 \mathrm{~m}$ unassisted. Persons with a diagnosis of dementia were excluded. In addition, persons were also excluded if their cognitive function on the Modified Mini Mental State Examination (3MSE) ${ }^{21}$ was so low as to be concerning for dementia. Education- and race/ethnicity-based cutoffs were employed. Participants with $<9$ years of education were excluded if their 3MSE score was $<70$ for African Americans and Spanish speakers or $<76$ for English-speaking, non-African Americans. Participants with $\geq 9$ years of education were excluded if their 3MSE score was $<76$ for African Americans and $<80$ for Spanish speakers and English-speaking, non-African Americans. The intervention consisted of aerobic, strength, flexibility, and balance training, with a general weekly walking goal of 150 minutes at moderate intensity, and at least two sessions per week of strength, flexibility, and balance exercise.

\section{Cognition hypotheses for the LIFE Study}

The primary outcome for the LIFE Study was the incidence of major mobility disability. The outcomes assessed by the LIFE Cognition Study represent secondary and tertiary aims of the LIFE Study. Our hypothesis was that compared with participants randomly assigned to SA health education, participants randomly assigned to structured PA would demonstrate:

- Better cognitive function, specifically processing speed and memory, as measured by the Digit Symbol Coding (DSC) task from the Wechsler Adult Intelligence Scale - Third Edition and the Hopkins Verbal Learning Test - Revised (HVLT-R) (secondary outcomes of LIFE);

- Better overall cognitive performance measured with a composite of all cognitive measures (tertiary outcome of LIFE); and

- Lower risk of the combined outcome of all-cause MCI or dementia.

\section{Cognitive measures}

Cognitive function was assessed by trained, certified neurocognitive technicians, using a pencil and paper battery and a computerized battery. For 21 Spanish speakers, the tests were administered in Spanish by a native speaker, using validated Spanish versions of the 3MSE, HVLT-R, and DSC. Directions for the other tests were translated by a professional translator.

\section{Pencil and paper cognitive battery}

These well-validated tests were selected to measure an array of cognitive domains. At baseline, the tests included the $3 \mathrm{MSE},{ }^{21}$ the DSC task from the Wechsler Adult Intelligence Scale - Third Edition, ${ }^{22}$ the HVLT-R, ${ }^{23}$ and the modified Rey-Osterrieth Complex Figure (mROCF) ${ }^{24}$ copy. The $3 \mathrm{MSE}$ is a test of global cognitive function that assesses a broad variety of cognitive measures and is scored 0-100, with higher scores indicating better performance. The DSC is a measure of attention, working memory, and psychomotor speed. ${ }^{25}$ Participants must transcribe a code into a series of numbered boxes as quickly and accurately as possible. 
The score is the number of correct symbols (0-133) transcribed in 120 seconds. The HVLT-R is a 12 -item word list learning and memory test. The list is repeated three times, generating a sum of the learning trials ( $0-36$ points). After a 20-minute delay, participants are asked to recall the words (0-12). In the mROCF copy, a measure of visuospatial skill, participants are asked to copy a complex geometric figure. The score is the number of correct elements copied (0-24). At year 2 of follow up, the above tests were readministered along with a 15-item version of the Boston Naming Test, ${ }^{26}$ the Trail Making Test (TMT), ${ }^{27}$ and the Category Fluency for Animals test. The Boston Naming Test is a test of confrontation naming whereby participants are shown a series of pencil drawings and asked to name the drawn objects. The TMT is a test of visuomotor speed (part A) and executive function (part B). In TMT-A, participants are asked to draw a line connecting circled numbers from 1 to 25 as fast and accurately as possible. The score is the time (0-300 seconds) required to connect the circles. In TMT-B, participants are asked to draw a line connecting ascending, alternating, numbers and letters (1-A-2-B-3-C, etc). The score is the time ( $0-300$ seconds) required to complete the task. The test is stopped if participants cannot complete it in 300 seconds or if five errors are made, in which case, the scores of 300 seconds and five errors are recorded. The Category Fluency for Animals test is a test of verbal fluency and executive function. Participants are asked to generate the names of as many animals as possible in 60 seconds. To determine whether any cognitive impairment has impacted functioning in daily living, we administered the Functional Assessment Questionnaire (FAQ) ${ }^{28}$ to an informant for each participant who scored $\leq 88$ on the 3MSE. Depression, which may affect cognitive performance, was assessed with the eleven-item version of the Center for Epidemiologic Studies Depression scale (CES-D) ${ }^{29}$ which queries depressive symptoms experienced in the previous week. Scores are transformed, using the procedure recommended by Kohout et al to make it compatible with the full 20-item instrument. ${ }^{30}$ Total scores range from 0 to 60 , with higher scores indicating more depressive symptoms.

\section{Computerized battery}

Following a successful pilot study, ${ }^{31}$ a battery of computerized cognitive tests was selected to add greater sensitivity for measuring speed of processing and executive function. This was administered on a laptop at baseline and either 18 or 30 months. Initially, the follow-up computerized battery was planned at year 2, but sites and the Steering Committee felt that participant burden was too high at that visit. Thus, the computerized battery was moved to month 18 for most participants and month 30 for those who had already completed the month 18 visit when the protocol was changed $(n=403)$. Three tasks were chosen as each tapped an aspect of executive function that has previously been shown to improve in older adults following a PA intervention designed to enhance aerobic fitness. ${ }^{32,33}$ They included the n-back task (1-back and 2-back), ${ }^{34,35}$ the Eriksen flanker task, ${ }^{36}$ and a task switching paradigm. ${ }^{36,37}$ The n-back task requires participants to use working memory to identify items presented nth places ( 1 or 2) earlier in a sequence and is evaluated by calculating the difference between hits (correct identifications) and false alarms (items incorrectly identified as occurring nth places earlier). Selective attention and the ability to inhibit the effect of distracting information were measured using the flanker task, in which participants are asked to indicate which direction the central arrow is pointing. In the flanker task, the central arrows are flanked by either congruent (arrows pointing in the same direction) or incongruent items (arrows pointing in the opposite direction). Reaction times (RT) for correct responses were measured for both congruent and incongruent conditions. Participants should respond more slowly in the incongruent condition relative to the congruent condition, and the difference score, computed by subtracting congruent RTs from incongruent RTS, should be smaller for those with better inhibitory processing. The task switching measure assesses attentional flexibility by having participants alternate between performing two different tasks using the same stimuli (letter/ digit pairs). Participants are asked to make a judgment about either the letter or the digit, and consecutive trials require the same (nonswitch trials) or the other judgment task (switch trials). Similar to the flanker task, RTs are calculated, for correct responses on switch and nonswitch trials, along with a difference score, in which nonswitch RTs are subtracted from switch RTs. Switch RTs are expected to be greater than nonswitch RTs, and a smaller difference score is associated with better cognitive flexibility.

\section{Adjudication of incident $\mathrm{MCl} / \mathrm{D}$}

Incident all-cause combined $\mathrm{MCI} / \mathrm{D}$ is an exploratory outcome of the LIFE Study. Classification of participants into one of three categories - no impairment, MCI, or dementia - is adjudicated by clinicians with expertise in the diagnosis of cognitive impairment (neurologists, geriatricians, psychiatrists, and geropsychologists). The criteria for MCI and dementia are based on modified 2011 National Institute on Aging Alzheimer's Association clinical consensus criteria. ${ }^{38,39}$ 
The criteria for MCI in the LIFE Study are: 1) objective impairment ( $>1.5$ standard deviation [SD] below the ageand education-adjusted means) in one or more cognitive domains in the pencil and paper test battery; 2) cognitive decline compared with previous scores or from estimated premorbid functioning, based on comparison with ageand education-appropriate normative data; 3) absence of significant functional impairment, based on the FAQ; and 4) criteria for dementia are not met. MCI is further subclassified into four possible subtypes: amnestic single domain, amnestic multidomain, non-amnestic single domain, and non-amnestic multidomain MCI. The dementia criteria are: 1) objective impairment ( $>1.5$ SD below age- and educationadjusted means) in two or more cognitive domains in the test battery; 2) decline compared with previous scores or from estimated premorbid functioning, based on comparison with age- and education-appropriate normative data; 3 ) evidence that cognitive deficits significantly interfere with ability to function at usual activities, based on the FAQ; and 4) deficits are not explained by delirium or major psychiatric disorder, as assessed at the annual visit and by review of supplemental data (eg, CES-D scores, records of hospitalizations, etc).

Each case is assigned to two reviewers blinded to the intervention assignment. Reviewers have access to participants' demographics, test scores, medical history, medications, any hospitalizations or serious adverse events, self-reported functional status (disability questionnaire), depression score, FAQ score, and the tester's notes about vision or hearing impairment or any other problems during the testing. Disagreements are discussed until resolved by group consensus on regularly scheduled conference calls (Figure 1). Baseline and year 2 cases are adjudicated so that incident MCI and dementia cases (as well as progression from MCI to dementia) can be ascertained.

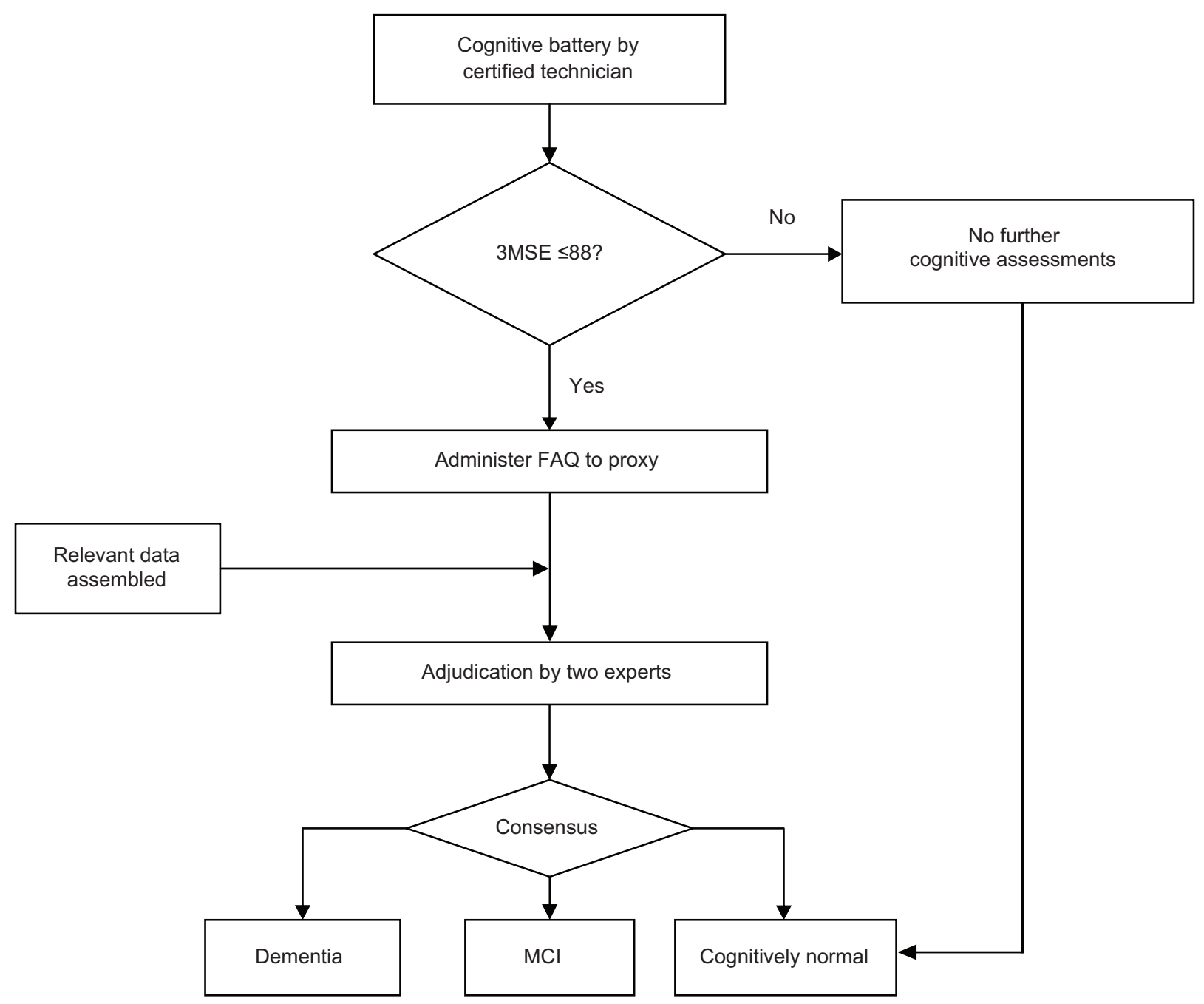

Figure I Flow diagram for cognitive classification.

Abbreviations: 3MSE, modified Mini Mental Status Examination; FAQ, Functional Assessment Questionnaire; MCl, mild cognitive impairment. 


\section{Analyses}

The primary outcome for the LIFE Study is the incidence of major mobility disability. ${ }^{18}$ The outcomes assessed by the LIFE Cognition Study represent secondary and tertiary aims of the LIFE Study. The LIFE Cognition Study has prespecified a structured approach to guide the analysis and interpretation of its cognitive endpoints. Its principal findings will be the relative impact of random assignment to the PA versus SA interventions on two outcomes: the DSC (overall) score and the average of the immediate and delayed recall scores from the HVLT-R. The LIFE Cognition Study has been powered based on these outcomes. Separate inferences (two-tailed type 1 error of 0.05 ) for differences in the year 2 means for the DSC and HVLT-R will be based on analyses of covariance (with markers for clinic site, sex, and baseline scores as covariates). Four subgroup comparisons have been prespecified for the principal DSC and HVLT-R scores, defined by baseline SPPB scores ( $<8$ versus $\geq 8$ ), baseline 3 MSE ( $<90$ versus $\geq 90$ ), sex, and age ( $70-79$ years versus $\geq 80$ years).

Support for findings from these inferences will primarily derive from parallel analyses of the following outcomes:

- Year 2 performance on the 3MSE,

- Year 2 performance on the mROCF copy,

- A composite from the year 2 pencil and paper tests, formed by averaging standardized scores from the DSC, HVLT-R, 3MSE, and mROCF.

- Mean congruent and noncongruent scores from the Eriksen flanker task (at 18 or 30 months),

- Mean switching and nonswitching scores from the task switching tests,

- Correct 1-back and 2-back test scores,

- A composite formed by averaging standardized scores from the four computer battery scores listed above, and

- An overall score calculated by averaging standardized scores from all the tests listed above.

For the exploratory aim to assess whether assignment to PA versus SA affects the incidence of $\mathrm{MCI} / \mathrm{D}$ across 2 years, logistic regression will be used to assess whether the proportion of participants diagnosed with $\mathrm{MCI} / \mathrm{D}$ varies by intervention assignment. Baseline adjudicated status for MCI, the level of global cognitive function (3MSE score), clinical site, and education status $(<$ high school, high school graduate) will be used as covariates in this analysis. Prespecified subgroups will be the same as used for the primary outcome.

In this manuscript, we present the baseline characteristics and baseline cognitive performance. We show comparisons across protocol prespecified subgroups, based on SPPB scores and race/ethnicity. Comparisons were made using Student's $t$-tests, for continuous, normally distributed measures, and the Wilcoxon signed-rank test for continuous, nonnormally distributed measures; chi-square tests were used to compare categorical variables.

\section{Results}

Characteristics of the randomized participants $(n=1,635)$ are shown in Table 1, and most of these have been previously published. ${ }^{40}$ Briefly, participants had a mean (SD) age of 78.9 (5.2) years; $67.2 \%$ were female, and $78.9 \%$ were White. The participants were well-educated, with $67.2 \%$ having

Table I Characteristics of the Life Cognition Study participants

\begin{tabular}{|c|c|}
\hline Characteristic & Mean (SD) or \% \\
\hline Age (years) & $78.9(5.23)$ \\
\hline Female & $67.2 \%$ \\
\hline \multicolumn{2}{|l|}{ Race/ethnicity* } \\
\hline Non-Hispanic white & $78.9 \%$ \\
\hline African American & $18.2 \%$ \\
\hline Asian & $1.0 \%$ \\
\hline Hispanic & $3.7 \%$ \\
\hline Other & $1.2 \%$ \\
\hline \multicolumn{2}{|l|}{ Education } \\
\hline$>$ High school & $67.2 \%$ \\
\hline Some high school/high school & $30.1 \%$ \\
\hline \multicolumn{2}{|l|}{ graduation/GED (years 9-12) } \\
\hline$<$ High school (years 0-8) & $2.8 \%$ \\
\hline Alcoholic drinks per week & $1.8(3.5)$ \\
\hline 0 drinks & $61.2 \%$ \\
\hline I-2 drinks & $17.9 \%$ \\
\hline $3-5$ drinks & $8.2 \%$ \\
\hline 6-7 drinks & $5.5 \%$ \\
\hline$\geq 8$ drinks & $7.2 \%$ \\
\hline \multicolumn{2}{|l|}{ Smoking status } \\
\hline Never-smoked & $51.9 \%$ \\
\hline Former smoker & $45.0 \%$ \\
\hline Current smoker & $3.1 \%$ \\
\hline BMI $\left(\mathrm{kg} / \mathrm{m}^{2}\right)$ & $30.2(6.08)$ \\
\hline SPPB score & $7.4(1.6 I)$ \\
\hline $4 \mathrm{~m}$ gait speed $(\mathrm{m} / \mathrm{sec})$ & $0.76(0.16)$ \\
\hline \multicolumn{2}{|l|}{ Chronic conditions } \\
\hline Hypertension & $71.0 \%$ \\
\hline Diabetes & $25.4 \%$ \\
\hline History of stroke/TIA & $6.7 \%$ \\
\hline Creatinine (mg/dL) & $0.96(0.33)$ \\
\hline Epworth sleepiness scale score $>10$ & $9.6 \%$ \\
\hline CES-D mean (SD) & $9.2(8.4)$ \\
\hline$\%$ score $>15$ & $19.6 \%$ \\
\hline $\mathrm{MCl}$ & $8.6 \%$ \\
\hline Dementia $^{\wedge}$ & $0.3 \%$ \\
\hline
\end{tabular}

Notes: $\mathrm{N}=1,635$. *Participant could respond "YES" to more than one race/ethnic group. ^Five participants were randomized who were later adjudicated to have dementia at baseline. They will be excluded from the incident dementia outcome. Abbreviations: BMI, body mass index; CES-D, Center for Epidemiologic Studies Depression scale; GED, General Education Diploma; SD, standard deviation; SPPB, short physical performance battery; TIA, transient ischemic attack. 
greater than high school education. The mean (SD) SPPB score at baseline was 7.4 (1.61), with a relatively slow gait speed $(0.76 \mathrm{~m} / \mathrm{s}[0.16])$. Participants who were excluded for low 3MSE ( $\mathrm{n}=120)$ but who were otherwise eligible, were older (mean [SD] age was 80.4 [5.1] versus 78.3 [5.2]) $(P<0.0001)$ and less likely to be White $(66.7 \%$ versus $78.9 \%)$ $(P=0.002)$ compared with the randomized participants. Ineligible participants were also less likely to be married $(21.7 \%$ versus $35.7 \%)(P<0.001)$ and were less likely to have attended college ( $34.9 \%$ versus $67.6 \%)(P<0.0001)$. In spite of the exclusion criteria for dementia and poor 3MSE scores, five participants were adjudicated to have dementia at baseline $(0.3 \%)$. They will be excluded from the incident $\mathrm{MCI} / \mathrm{D}$ outcome. Participants adjudicated to have MCI at baseline $(8.6 \%)$ will be eligible for the dementia outcome.

In Table 2, we present the baseline mean or median cognitive test scores for the entire cohort and by prespecified subgroups. The baseline median (interquartile range [IQR]) 3MSE score of the LIFE participants was 93 (88-96); the DSC score was 46 (38-54); and the mROCF copy score was 17.5 (15-20). The mean (SD) HVLT-R delayed recall was 7.7 (2.8) words. Scores for participants with poorer physical performance (SPPB performance of $\leq 7$ ) were significantly lower than those for participants with better baseline physical performance (SPPB 8-9) in all tests except the mROCF copy (Table 2). Baseline scores for non-White participants were also lower than for Whites (all $P<0.001$ ) (Table 2). On the computerized tasks, participants with poorer physical function scored lower on 1- and 2-back accuracy and performed worse at task switching. For non-White participants, only 2-back accuracy was worse when compared with White participants. Though non-White participants had slower reaction times than did Whites on both task switching and the flanker task, the difference scores were not lower for non-Whites, suggesting that they were not performing worse in terms of the executive function component of the tasks (Table 2).

\section{Discussion}

The LIFE Study is, to our knowledge, the largest and longest trial of PA with cognitive outcomes in older sedentary adults at increased risk for incident mobility disability. Observational studies have linked self-reported PA to better cognitive function and less cognitive decline over time. ${ }^{11-13}$ This RCT is testing these observations by assessing whether a PA program primarily focused on walking prevents cognitive decline in older adults. The results could have particular importance given the exponential rise in the number of older adults in developed countries and a consonant rise in the prevalence and incidence of MCI and dementia along with the associated personal and societal costs for these conditions. Adding to its potential impact is the fact that the LIFE Study intervention can be easily implemented in a broad spectrum of communities and recommended by primary care physicians, and is consistent with national recommendations for 150 minutes of PA per week. ${ }^{41}$

The baseline cognitive function of the LIFE cohort, measured by the 3MSE, was similar to that of other clinical trials of older adults assessing cognitive outcomes. For example, in the Ginkgo Evaluation of Memory Study, the mean age (79.1 years) and mean 3MSE scores (93.4) were very close to those of the LIFE Study. ${ }^{42}$ In the Women's Health Initiative Memory Study, the mean 3MSE score was 95.1, but participants were younger. ${ }^{43}$ In the RCT of the effect of exercise on cognitive outcomes in persons with subjective memory complaints (no dementia) by Lautenschlager et al the mean age of participants was $68.7(n=170)$, and their mean DSC performance was $54.3^{16}$ compared with a median performance of 46 in LIFE participants (who are older, more frail, and more ethnically diverse). The LIFE cognitive battery measures several key cognitive functions - global cognitive function, executive function, processing speed, memory, language, and visuospatial function. As expected, our baseline data confirms that participants with poorer physical performance also had poorer cognitive performance. An important question that the LIFE Study will be able to answer is whether the impact of a structured PA program has the same effect on cognition regardless of baseline physical function.

Incident all-cause MCI/D is an exploratory outcome of the LIFE Study because it is unlikely that we will observe a statistically significant between-group difference in incident $\mathrm{MCI} / \mathrm{D}$ due to anticipated low power and relatively short duration of follow-up (2 years). Due to the slowly progressive nature of Alzheimer's disease, by far the most common cause of dementia, ${ }^{44}$ and the long lag between the development of brain pathology and clinical manifestations, ${ }^{45}$ longer follow up will likely be needed to determine whether this 2-year intervention will have beneficial effects on incident MCI/D.

In conclusion, the LIFE Study will provide important information on the effects of a long-term structured PA program on cognitive outcomes in older sedentary adults at heightened risk for mobility disability. In addition to its importance in the area of prevention of cognitive decline, the LIFE Study will likely contribute additional useful information relating to exercise and other behavioral intervention delivery in older adults. 


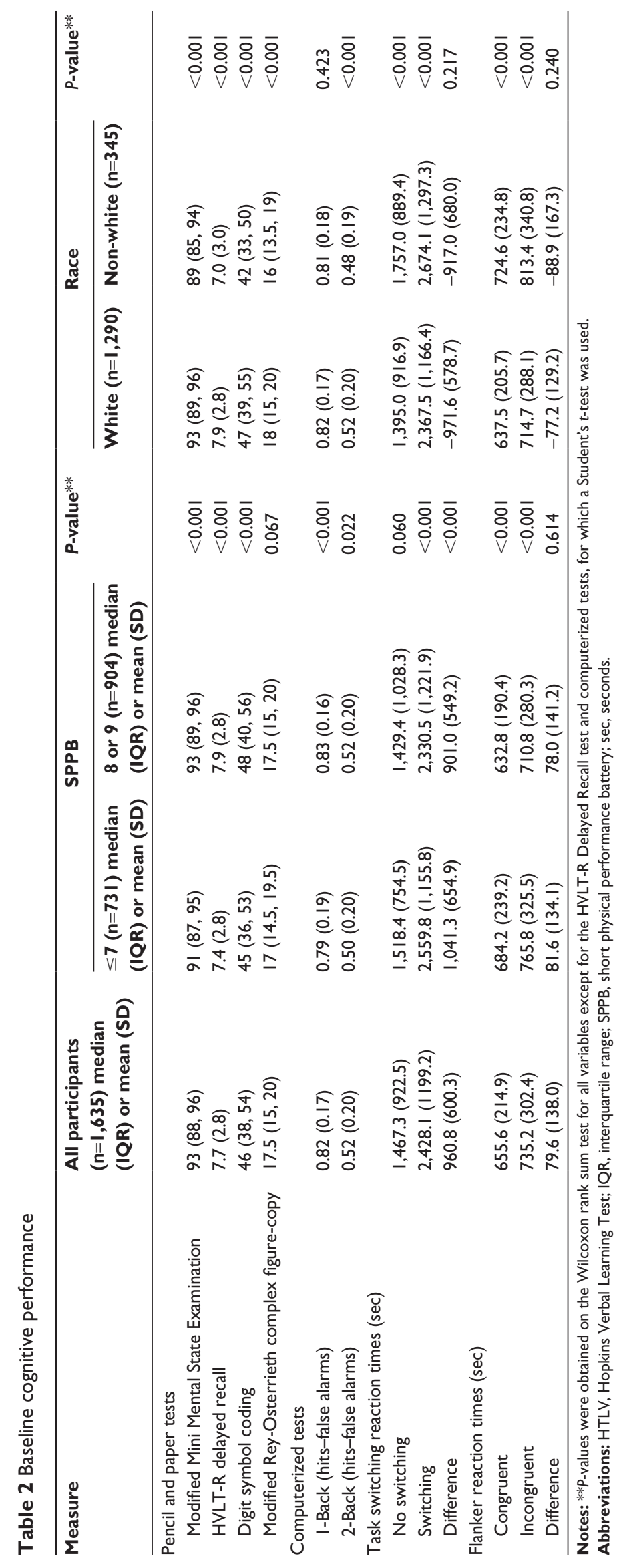




\section{Acknowledgments}

The LIFE Study Investigators are listed in Figure S1.

The Lifestyle Interventions and Independence for Elders Study is funded by a National Institutes of Health (NIH)/ National Institute on Aging Cooperative Agreement (number UO1 AG22376) and a supplement from the National Heart, Lung and Blood Institute (number 3U01AG022376-05A2S), and is sponsored in part by the Intramural Research Program of the National Institute on Aging, NIH.

The research is also partially supported by the Claude D Pepper Older Americans Independence Centers at the University of Florida (grant number 1 P30 AG028740), Wake Forest University (grant number 1 P30 AG21332), Tufts University (grant number 1 P30 AG031679), University of Pittsburgh (grant number P30 AG024827), and Yale University (grant number P30 AG021342), and the NIH/National Center for Research Resources (NCRR) Clinical and Translational Science Award (CTSA) at Stanford University (number UL1 RR025744).

The Tufts University LIFE field center is also supported by the Boston Rehabilitation Outcomes Center (grant number 1R24HD065688-01A1). Any opinions, findings, conclusion, or recommendations expressed in this publication are those of the authors and do not necessarily reflect the view of the US Department of Agriculture.

Dr Thomas Gill (Yale University) is the recipient of an Academic Leadership Award (number K07AG3587) from the National Institute on Aging.

\section{Disclosure}

The authors report no conflicts of interest in this work.

\section{References}

1. Cotman CW, Berchtold NC. Exercise: a behavioral intervention to enhance brain health and plasticity. Trends Neurosci. 2002;25(6):295-301.

2. Black JE, Isaacs KR, Anderson BJ, Alcantara AA, Greenough WT. Learning causes synaptogenesis, whereas motor activity causes angiogenesis, in cerebellar cortex of adult rats. Proc Natl Acad Sci U S A. 1990; 87(14):5568-5572.

3. Colcombe SJ, Erickson KI, Raz N, et al. Aerobic fitness reduces brain tissue loss in aging humans. J Gerontol A Biol Sci Med Sci. 2003;58(2): 176-180.

4. Colcombe SJ, Erickson KI, Scalf PE, et al. Aerobic exercise training increases brain volume in aging humans. J Gerontol A Biol Sci Med Sci. 2006;61(11):1166-1170.

5. Burdette JH, Laurienti PJ, Espeland MA, et al. Using network science to evaluate exercise-associated brain changes in older adults. Front Aging Neurosci. 2010;2:23.

6. Erickson KI, Prakash RS, Voss MW, et al. Brain-derived neurotrophic factor is associated with age-related decline in hippocampal volume. J Neurosci. 2010;30(15):5368-5375.

7. Erickson KI, Voss MW, Prakash RS, et al. Exercise training increases size of hippocampus and improves memory. Proc Natl Acad Sci US A. 2011;108(7):3017-3022.
8. Erickson KI, Prakash RS, Voss MW, et al. Aerobic fitness is associated with hippocampal volume in elderly humans. Hippocampus. 2009; 19(10):1030-1039.

9. Erickson KI, Raji CA, Lopez OL, et al. Physical activity predicts gray matter volume in late adulthood: the Cardiovascular Health Study. Neurology. 2010;75(16):1415-1422.

10. Adlard PA, Perreau VM, Pop V, Cotman CW. Voluntary exercise decreases amyloid load in a transgenic model of Alzheimer's disease. J Neurosci. 2005;25(17):4217-4221.

11. Yaffe K, Barnes D, Nevitt M, Lui LY, Covinsky K. A prospective study of physical activity and cognitive decline in elderly women: women who walk. Arch Intern Med. 2001;161(14):1703-1708.

12. Larson EB, Wang L, Bowen JD, et al. Exercise is associated with reduced risk for incident dementia among persons 65 years of age and older. Ann Intern Med. 2006;144(2):73-81.

13. Abbott RD, White LR, Ross GW, Masaki KH, Curb JD, Petrovitch H. Walking and dementia in physically capable elderly men. JAMA. 2004; 292(12):1447-1453.

14. Kramer AF, Hahn S, Cohen NJ, et al. Ageing, fitness and neurocognitive function. Nature. 1999;400(6743):418-419.

15. Klusmann V, Evers A, Schwarzer R, et al. Complex mental and physical activity in older women and cognitive performance: a 6-month randomized controlled trial. J Gerontol A Biol Sci Med Sci. 2010;65(6): 680-688.

16. Lautenschlager NT, Cox KL, Flicker L, et al. Effect of physical activity on cognitive function in older adults at risk for Alzheimer disease: a randomized trial. JAMA. 2008;300(9):1027-1037.

17. Williamson JD, Espeland M, Kritchevsky SB, et al; LIFE Study Investigators. Changes in cognitive function in a randomized trial of physical activity: results of the lifestyle interventions and independence for elders pilot study. J Gerontol A Biol Sci Med Sci. 2009;64(6):688-694.

18. Fielding RA, Rejeski WJ, Blair S, et al; LIFE Research Group. The Lifestyle Interventions and Independence for Elders Study: design and methods. J Gerontol A Biol Sci Med Sci. 2011;66(11):1226-1237.

19. Guralnik JM, Ferrucci L, Simonsick EM, Salive ME, Wallace RB. Lowerextremity function in persons over the age of 70 years as a predictor of subsequent disability. $N$ Engl J Med. 1995;332(9):556-561.

20. Guralnik JM, Simonsick EM, Ferrucci L, et al. A short physical performance battery assessing lower extremity function: association with self-reported disability and prediction of mortality and nursing home admission. J Gerontol. 1994;49(2):M85-M94.

21. Teng EL, Chui HC. The Modified Mini-Mental State (3MS) examination. J Clin Psychiatry. 1987;48(8):314-318.

22. Wechsler D. WAIS-R Manual: Wechsler Adult Intelligence Scale Revised. New York, NY: Psychological Corporation; 1981.

23. Brandt J, Benedict RHB. Hopkins Verbal Learning Test-Revised: Professional Manual. Lutz, FL: Psychological Assessment Resources, Inc; 2001.

24. Becker JT, Boller F, Saxton J, McGonigle-Gibson KL. Normal rates of forgetting of verbal and non-verbal material in Alzheimer's disease. Cortex. 1987;23(1):59-72.

25. Salthouse TA. The role of memory in the age decline in digit-symbol substitution performance. J Gerontol. 1978;33(2):232-238.

26. Kaplan E, Goodglass H, Weintraub S. The Boston Naming Test. 2nd ed. Philadelphia, PA: Lea \& Febiger; 1983.

27. Reitan RM. Trail Making Test. Manual for Administration and Scoring. Tucson, AZ: Neuropsychological Laboratory; 1992.

28. Pfeffer RI, Kurosaki TT, Harrah CH, Chance JM, Filos S. Measurement of functional activities in older adults in the community. J Gerontol. 1982;37(3):323-329.

29. Radloff LS. The CES-D Scale: A self-report depression scale for research in the general population. Appl Psychol Meas. 1977;1(3): 385-401.

30. Kohout FJ, Berkman LF, Evans DA, Cornoni-Huntley J. Two shorter forms of the CES-D (Center for Epidemiological Studies Depression) depression symptoms index. J Aging Health. 1993;5(2): 179-193. 
31. Espeland MA, Katula JA, Rushing J, et al; LIFE Study Group. Performance of a computer-based assessment of cognitive function measures in two cohorts of seniors. Int $J$ Geriatr Psychiatry. 2013;28(12):1239-1250.

32. Colcombe S, Kramer AF. Fitness effects on the cognitive function of older adults: a meta-analytic study. Psychol Sci. 2003;14(2):125-130.

33. Kramer AF, Hahn S, McAuley E, McAuley E. Exercise, aging and cognition: healthy body, healthy mind? In: Rogers WA, Fisk AD, editors. Human Factors Interventions for the Health Care of Older Adults. Mahwah, NJ: Laurence Erlbaum Associates Publishing; 2001: 91-120.

34. Dobbs AR, Rule BG. Adult age differences in working memory. Psychol Aging. 1989;4(4):500-503.

35. Jonides J, Schumacher EH, Smith EE, et al. Verbal Working Memory Load Affects Regional Brain Activation as Measured by PET. J Cogn Neurosci. 1997;9(4):462-475.

36. Eriksen BA, Eriksen CW. Effects of noise letters upon the identification of a target letter in a nonsearch task. Percept Psychophys. 1974;16(1):143-149.

37. Rogers RD, Monsell S. The cost of a predictable switch between simple cognitive tasks. J Exp Psychol Gen. 1995;124:207-231.

38. Albert MS, DeKosky ST, Dickson D, et al. The diagnosis of mild cognitive impairment due to Alzheimer's disease: recommendations from the National Institute on Aging-Alzheimer's Association workgroups on diagnostic guidelines for Alzheimer's disease. Alzheimers Dement. 2011;7(3):270-279.
39. McKhann GM, Knopman DS, Chertkow H, et al. The diagnosis of dementia due to Alzheimer's disease: recommendations from the National Institute on Aging-Alzheimer's Association workgroups on diagnostic guidelines for Alzheimer's disease. Alzheimers Dement. 2011;7(3):263-269.

40. Marsh AP, Lovato LC, Glynn NW, et al; LIFE Study Research Group. Lifestyle interventions and independence for elders study: recruitment and baseline characteristics. J Gerontol A Biol Sci Med Sci. 2013; 68(12):1549-1558.

41. Physical Activity Guidelines writing group. 2008 Physical Activity Guidelines for Americans. Washington, DC: US Department of Health and Human Services; 2008.

42. Snitz BE, O’Meara ES, Carlson MC, et al; Ginkgo Evaluation of Memory (GEM) Study Investigators. Ginkgo biloba for preventing cognitive decline in older adults: a randomized trial. JAMA. 2009;302(24):2663-2670.

43. Rapp SR, Espeland MA, Hogan P, Jones BN, Dugan E; WHIMS investigators. Baseline experience with Modified Mini Mental State Exam: The Women's Health Initiative Memory Study (WHIMS). Aging Ment Health. 2003;7(3):217-223.

44. Plassman BL, Langa KM, Fisher GG, et al. Prevalence of dementia in the United States: the aging, demographics, and memory study. Neuroepidemiology. 2007;29(1-2):125-132.

45. Jack CR, Knopman DS, Jagust WJ, et al. Hypothetical model of dynamic biomarkers of the Alzheimer's pathological cascade. Lancet Neurol. 2010;9(1):119-128. 


\section{Supplementary material}

\begin{tabular}{|c|c|}
\hline $\begin{array}{l}\text { Administrative Coordinating Center, University } \\
\text { of Florida, Gainesville, FL }\end{array}$ & $\begin{array}{l}\text { Denise E Bonds, MD, MPH (National Heart, Lung and } \\
\text { Blood Institute) }\end{array}$ \\
\hline Marco Pahor, MD - Principal Investigator of the LIFE & Kushang V Patel, PhD (National Institute on Aging) \\
\hline \multicolumn{2}{|l|}{ Study } \\
\hline Jack M Guralnik, MD, PhD - Co-Investigator of the & Field centers \\
\hline LIFE Study (University of Maryland School of & Northwestern University, Chicago, IL \\
\hline Medicine, Baltimore, MD) & Mary M McDermott, MD - Field Center Principal \\
\hline Christiaan Leeuwenburgh, $\mathrm{PhD}$ & Investigator \\
\hline Connie Caudle & Bonnie Spring, PhD - Field Center Co-Investigator \\
\hline Lauren Crump, MPH & Joshua Hauser, MD - Field Center Co-Investigator \\
\hline Latonia Holmes & Diana Kerwin, MD - Field Center Co-Investigator \\
\hline Jocelyn Lee, PhD & Kathryn Domanchuk, BS \\
\hline \multirow[t]{2}{*}{ Ching-ju Lu, MPH } & Rex Graff, MS \\
\hline & Alvito Rego, MA \\
\hline \multicolumn{2}{|l|}{ Data Management, Analysis and Quality Control } \\
\hline Center, Wake Forest University, Winston Salem, NC & Pennington Biomedical Research Center, \\
\hline Michael E Miller, PhD - DMAQC Principal Investigator & Baton Rouge, LA \\
\hline Mark A Espeland, PhD - DMAQC Co-Investigator & Timothy S Church, MD, PhD, MPH - Field Center \\
\hline Walter T Ambrosius, $\mathrm{PhD}$ & Principal Investigator \\
\hline William Applegate, MD & Steven N Blair, PED (University of South Carolina) \\
\hline Daniel P Beavers, PhD, MS & Valerie H Myers, PhD \\
\hline Robert P Byington, $\mathrm{PhD}$, MPH, FAHA & Ron Monce, PA-C \\
\hline Delilah Cook, CCRP & Nathan E Britt, NP \\
\hline Curt D Furberg, MD, PhD & Melissa Nauta Harris, BS \\
\hline Lea N Harvin, BS & Ami Parks McGucken, MPA, BS \\
\hline Leora Henkin, MPH, Med & Ruben Rodarte, MBA, MS, BS \\
\hline John Hepler, MA & Heidi K Millet, MPA, BS \\
\hline Fang-Chi Hsu, PhD & Catrine Tudor-Locke, PhD, FACSM \\
\hline Laura Lovato, MS & Ben P Butitta, BS \\
\hline Wesley Roberson, BSBA & Sheletta G Donatto, MS, RD, LDN, CDE \\
\hline Julia Rushing, BSPH, MStat & Shannon H Cocreham, BS \\
\hline \multicolumn{2}{|l|}{ Scott Rushing, BS } \\
\hline Cynthia L Stowe, MPM & Stanford University, Palo Alto, CA \\
\hline Michael P Walkup, MS & Abby C King, PhD - Field Center Principal Investigator \\
\hline Don Hire, BS & Cynthia M Castro, PhD \\
\hline W Jack Rejeski, PhD & William L Haskell, PhD \\
\hline Jeffrey A Katula, PhD, MA & Randall S Stafford, MD, PhD \\
\hline Peter H Brubaker, $\mathrm{PhD}$ & Leslie A Pruitt, $\mathrm{PhD}$ \\
\hline Shannon L Mihalko, $\mathrm{PhD}$ & Veronica Yank, MD \\
\hline \multirow[t]{2}{*}{ Janine M Jennings, $\mathrm{PhD}$} & Kathy Berra, MSN, NP-C, FAAN \\
\hline & Carol Bell, NP \\
\hline National Institutes of Health, Bethesda, MD & Rosita M Thiessen \\
\hline Evan C Hadley, MD (National Institute on Aging) & Kate $\mathrm{P}$ Youngman, MA \\
\hline Sergei Romashkan, MD, PhD (National Institute & Selene B Virgen, BAS \\
\hline on Aging) & Eric Maldonado, BA \\
\hline
\end{tabular}

Figure SI (Continued) 


\author{
Kristina N Tarin, MS, CSCS \\ Heather Klaftenegger, BS \\ Carolyn A Prosak, RD \\ Ines Campero, BA \\ Dulce M Garcia, BS \\ José Soto, BA \\ Linda Chio, BA \\ David Hoskins, MS
}

\section{Tufts University, Boston, MA}

Roger A Fielding, $\mathrm{PhD}$ - Field Center Principal Investigator Miriam E Nelson, PhD - Field Center Co-Investigator

Sara C Folta, PhD - Field Center Co-Investigator

Edward M Phillips, MD

Christine K Liu, MD

Erica C McDavitt, MS

Kieran F Reid, MSc, MPH

Won S Kim, BS

Vince E Beard, BS

University of Florida, Gainesville, FL

Todd M Manini, PhD - Field Center Principal Investigator Marco Pahor, MD - Field Center Co-Investigator

Stephen D Anton, PhD

Susan Nayfield, MD

Thomas W Buford, PhD

Michael Marsiske, PhD

Bhanuprasad D Sandesara, MD

Jeffrey D Knaggs, BS

Megan S Lorow, BS

William C Marena, MT, CCRC

Irina Korytov, MD

Holly L Morris, MSN, RN, CCRC (Brooks Rehabilitation Clinical Research Center, Jacksonville, FL)

Margo Fitch, PT (Brooks Rehabilitation Clinical

Research Center, Jacksonville, FL)

Floris F Singletary, MS, CCC-SLP (Brooks Rehabilitation Clinical Research Center, Jacksonville, FL)

Jackie Causer, BSH, RN (Brooks Rehabilitation Clinical Research Center, Jacksonville, FL)

Katie A Radcliff, MA (Brooks Rehabilitation Clinical

Research Center, Jacksonville, FL)

University of Pittsburgh, Pittsburgh, PA

Anne B Newman, MD, MPH - Field Center Principal

Investigator
Stephanie A Studenski, MD, MPH - Field Center

Co-Investigator

Bret H Goodpaster, PhD

Nancy W Glynn, PhD

Oscar Lopez, MD

Neelesh K Nadkarni, MD, PhD

Kathy Williams, RN, BSEd, MHSA

Mark A Newman, PhD

George Grove, MS

Janet T Bonk, MPH, RN

Jennifer Rush, MPH

Piera Kost, BA (deceased)

Diane G Ives, MPH

Wake Forest University, Winston Salem, NC

Stephen B Kritchevsky, PhD - Field Center Principal

Investigator

Anthony P Marsh, PhD - Field Center Co-Investigator

Tina E Brinkley, $\mathrm{PhD}$

Jamehl S Demons, MD

Kaycee M Sink, MD, MAS

Kimberly Kennedy, BA, CCRC

Rachel Shertzer-Skinner, MA, CCRC

Abbie Wrights, MS

Rose Fries, RN, CCRC

Deborah Barr, MA, RHEd, CHES

Yale University, New Haven, CT

Thomas M Gill, MD - Field Center Principal

Investigator

Robert S Axtell, PhD, FACSM - Field Center

Co-Investigator (Southern Connecticut State University,

Exercise Science Department)

Susan S Kashaf, MD, MPH (VA Connecticut Healthcare System)

Nathalie de Rekeneire, MD, MS

Joanne M McGloin, MDiv, MS, MBA

Karen $\mathrm{C} \mathrm{Wu}, \mathrm{RN}$

Denise M Shepard, RN, MBA

Barbara Fennelly, MA, RN

Lynne P Iannone, MS, CCRP

Raeleen Mautner, PhD

Theresa Sweeney Barnett, MS, APRN

Sean N Halpin, MA

Matthew J Brennan, MA

Julie A Bugaj, MS

Figure SI (Continued) 


\begin{tabular}{|c|c|}
\hline Maria A Zenoni, MS & Eileen Handberg, PhD, ARNP \\
\hline \multirow[t]{2}{*}{ Bridget M Mignosa, AS } & Daniel Deluca, BS \\
\hline & James Hill, MD, MS, FACC \\
\hline Cognition Coordinating Center, Wake Forest & Anita Szady, MD \\
\hline \multicolumn{2}{|l|}{ University, Winston Salem, NC } \\
\hline Jeff Williamson, MD, MHS - Center Principal & Spirometry Reading Center, Yale University, \\
\hline Investigator & New Haven, CT \\
\hline Kaycee M Sink, MD, MAS - Center Co-Investigator & Geoffrey L Chupp, MD \\
\hline Hugh C Hendrie, MB, ChB, DSc (Indiana University) & Gail M Flynn, RCP, CRFT \\
\hline Stephen R Rapp, PhD & Thomas M Gill, MD \\
\hline Joe Verghese, MB, BS (Albert Einstein College of & John L Hankinson, PhD (Hankinson Consulting, Inc) \\
\hline Medicine of Yeshiva University) & Carlos A Vaz Fragoso, MD \\
\hline \multicolumn{2}{|l|}{ Nancy Woolard } \\
\hline Mark Espeland, $\mathrm{PhD}$ & Cost Effectiveness Analysis Center \\
\hline Janine Jennings, $\mathrm{PhD}$ & Erik J Groessl, PhD (University of California, San Diego \\
\hline \multirow[t]{2}{*}{ Valerie K Wilson, MD } & and VA San Diego Healthcare System) \\
\hline & Robert M Kaplan, PhD (Office of Behavioral and Social \\
\hline Electrocardiogram Reading Center, University & Sciences Research, National Institutes of Health) \\
\hline of Florida, Gainesville, FL & \\
\hline Carl J Pepine MD, MACC & \\
\hline Mario Ariet, $\mathrm{PhD}$ & \\
\hline
\end{tabular}

Figure SI Research investigators for the LIFE Study.

\section{Publish your work in this journal}

Clinical Interventions in Aging is an international, peer-reviewed journal focusing on evidence-based reports on the value or lack thereof of treatments intended to prevent or delay the onset of maladaptive correlates of aging in human beings. This journal is indexed on PubMed Central, MedLine,
CAS, Scopus and the Elsevier Bibliographic databases. The manuscript management system is completely online and includes a very quick and fair peer-review system, which is all easy to use. Visit http://www.dovepress. com/testimonials.php to read real quotes from published authors. 